\title{
Thermoresponsive dendronized poly(phenylacetylene)s showing tunable helicity
}

\author{
Fang Wang, † Congcong Zhou, $\$$ Kun Liu, Jiatao Yan, Wen Li,* \\ Toshio Masuda and Afang Zhang*
}

Department of Polymer Materials, International Joint Laboratory of Biomimetic \& Smart Polymers, School of Materials Science and Engineering, Shanghai University, Materials Building Room 447, Nanchen Street 333, Shanghai 200444, China. E-mails: wli@shu.edu.cn (W.L.), azhang@shu.edu.cn (A.Z.)

\section{Table of Contents}

Figure S1. ${ }^{1} \mathrm{H}$ NMR spectrum of monomer PA-ACe in $\mathrm{d}_{6}$-DMSO $\cdots \cdots \cdots \cdots \cdots \cdots, \mathrm{S} 3$

Figure S2. ${ }^{1} \mathrm{H}$ NMR spectrum of monomer PA-ACm in $\mathrm{d}_{6}$-DMSO $\cdots \cdots \cdots \cdots \cdots \cdot \mathrm{S} 3$

Figure S3. ${ }^{1} \mathrm{H}$ NMR spectrum of monomer PA-ES in $\mathrm{d}_{6}$-DMSO $\cdots \cdots \ldots \ldots \ldots \ldots, \mathrm{S} 4$

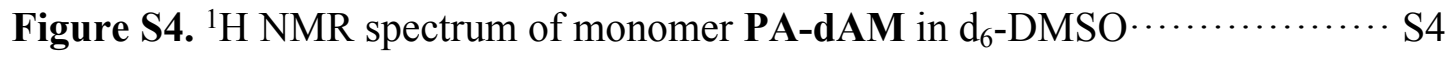

Figure S5. ${ }^{1} \mathrm{H}$ NMR spectrum of monomer PA-AM in $\mathrm{d}_{6}$-DMSO $\cdots \cdots \cdots \cdots \cdots \cdots$ S5

Figure S6. ${ }^{1} \mathrm{H} \quad \mathrm{NMR}$ spectrum of monomer PPA-ACe in $\mathrm{d}_{6}$-DMSO $\cdots \cdots \cdots \cdots \cdots \cdot \mathrm{S} 5$

Figure S7. ${ }^{1} \mathrm{H}$ NMR spectrum of monomer PPA-ACm in $\mathrm{d}_{6}$-DMSO $\cdots \cdots \ldots \ldots \ldots . .6$

Figure S8. ${ }^{1} \mathrm{H} \quad \mathrm{NMR}$ spectrum of monomer PPA-ES in

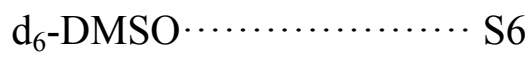


Figure S9. ${ }^{1} \mathrm{H} \quad$ NMR $\quad$ spectrum of monomer PPA-dAM in $\mathrm{d}_{6}$-DMSO $\cdots \cdots \cdots \cdots \cdot \ldots \cdot \mathrm{S} 7$

Figure S10. ${ }^{1} \mathrm{H} \quad$ NMR spectrum of monomer PPA-AM in $\mathrm{d}_{6}$-DMSO S7

Figure S11. Atomic force microscopy (AFM) image of PPA-ACm from THF $(0.002$ $\mathrm{mg} / \mathrm{mL})$ S8

Figure S12. Atomic force microscopy (AFM) image of PPA-ACe from THF (0.002 $\mathrm{mg} / \mathrm{mL}$ ) S8

Figure S13. CD and UV/vis spectra of PPA-ES $(0.25 \mathrm{mg} / \mathrm{mL})$ measured in $\mathrm{H}_{2} \mathrm{O}$, THF, $\mathrm{MeOH}, \quad \mathrm{DCM}$ and $\mathrm{CHCl}_{3}$, at $25^{\circ} \mathrm{C}$ S8

Figure S14. ${ }^{1} \mathrm{H}$ NMR spectra of monomer PA-ACm in $\mathrm{D}_{2} \mathrm{O}$ at various temperatures S9

Figure S15. ${ }^{1} \mathrm{H}-{ }^{1} \mathrm{H}$ NOESY spectrum of monomer PA-ACm in $\mathrm{D}_{2} \mathrm{O}$ at 10 ${ }^{\circ} \mathrm{C}$ S9

Figure S16. ${ }^{1} \mathrm{H}-{ }^{1} \mathrm{H}$ NOESY spectrum of monomer PA-ACm in $\mathrm{D}_{2} \mathrm{O}$ at 38 ${ }^{\circ} \mathrm{C} \cdot$ $\mathrm{S} 10$

Figure S17. Temperature variable CD spectra of PPA-dAM $(0.025 \mathrm{mg} / \mathrm{mL})$ taken after addition of $\mathrm{BaCl}_{2} \cdot \mathrm{H}_{2} \mathrm{O}(0.25 \mathrm{mg} / \mathrm{mL})$ $\mathrm{S} 10$ 


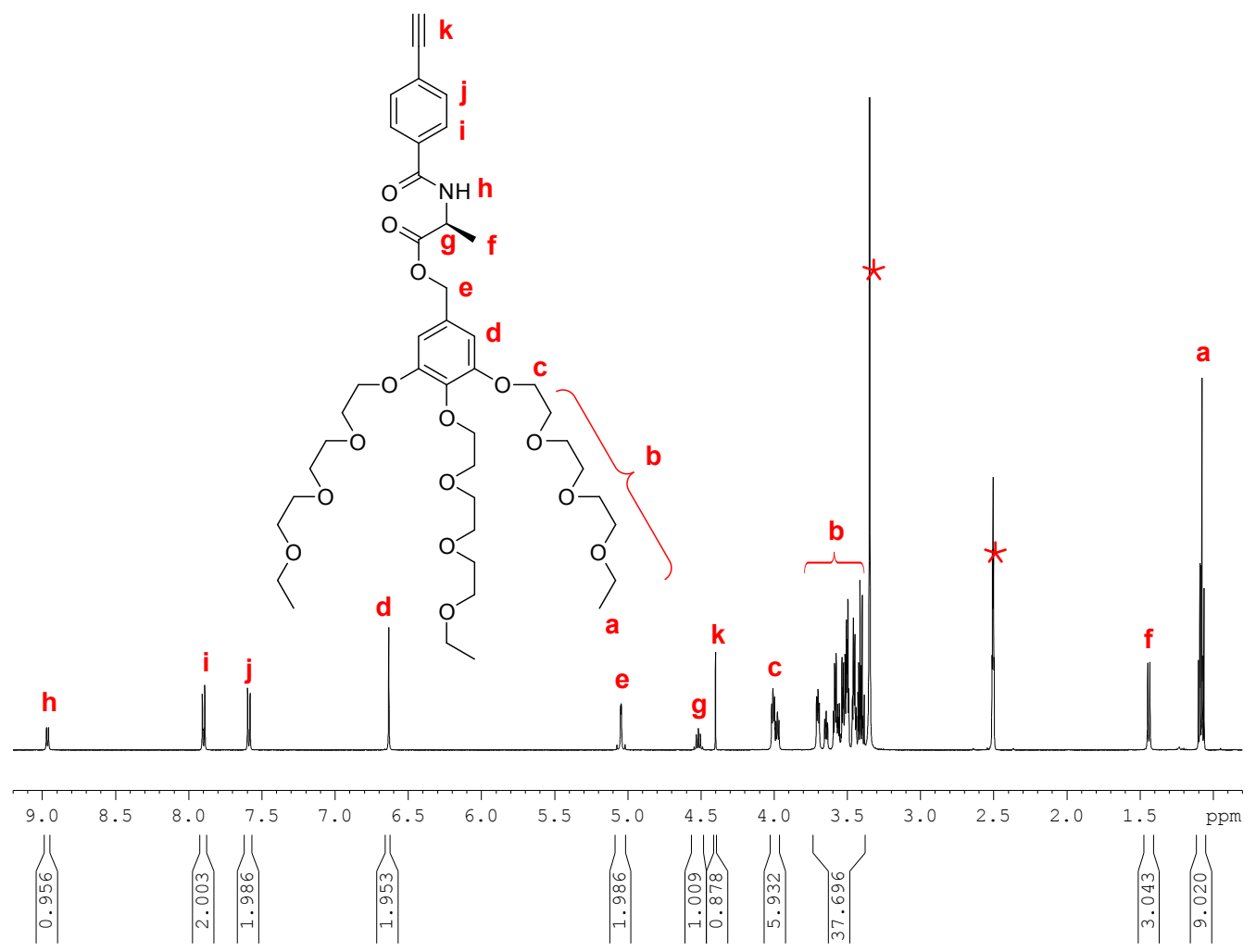

Figure S1. ${ }^{1} \mathrm{H}$ NMR spectrum of monomer PA-ACe in $\mathrm{d}_{6}$-DMSO. The solvent peak is marked with asterisk $(*)$.

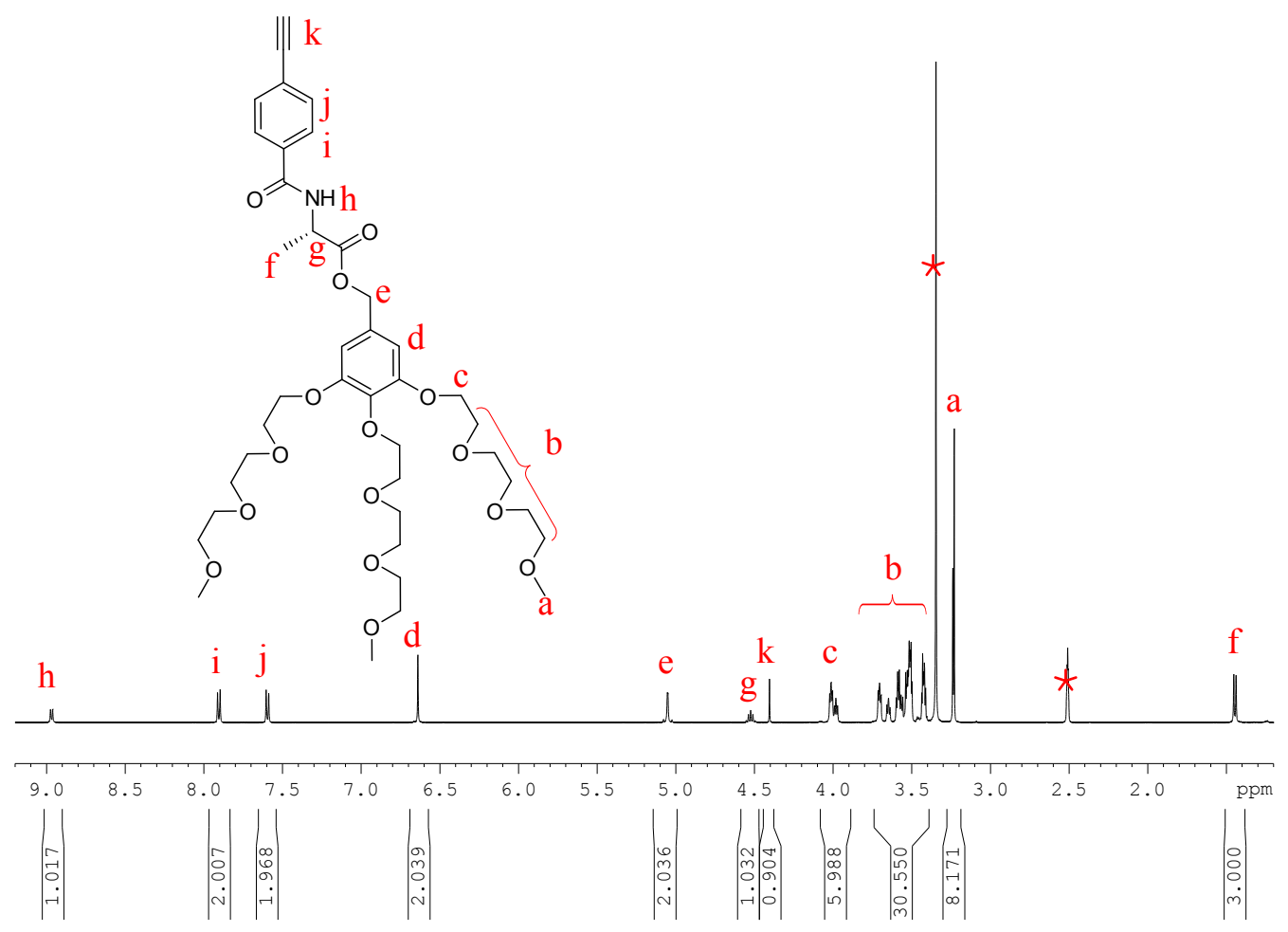

Figure S2. ${ }^{1} \mathrm{H}$ NMR spectrum of monomer PA-ACm in $\mathrm{d}_{6}$-DMSO. The solvent peak is marked with asterisk $(*)$. 


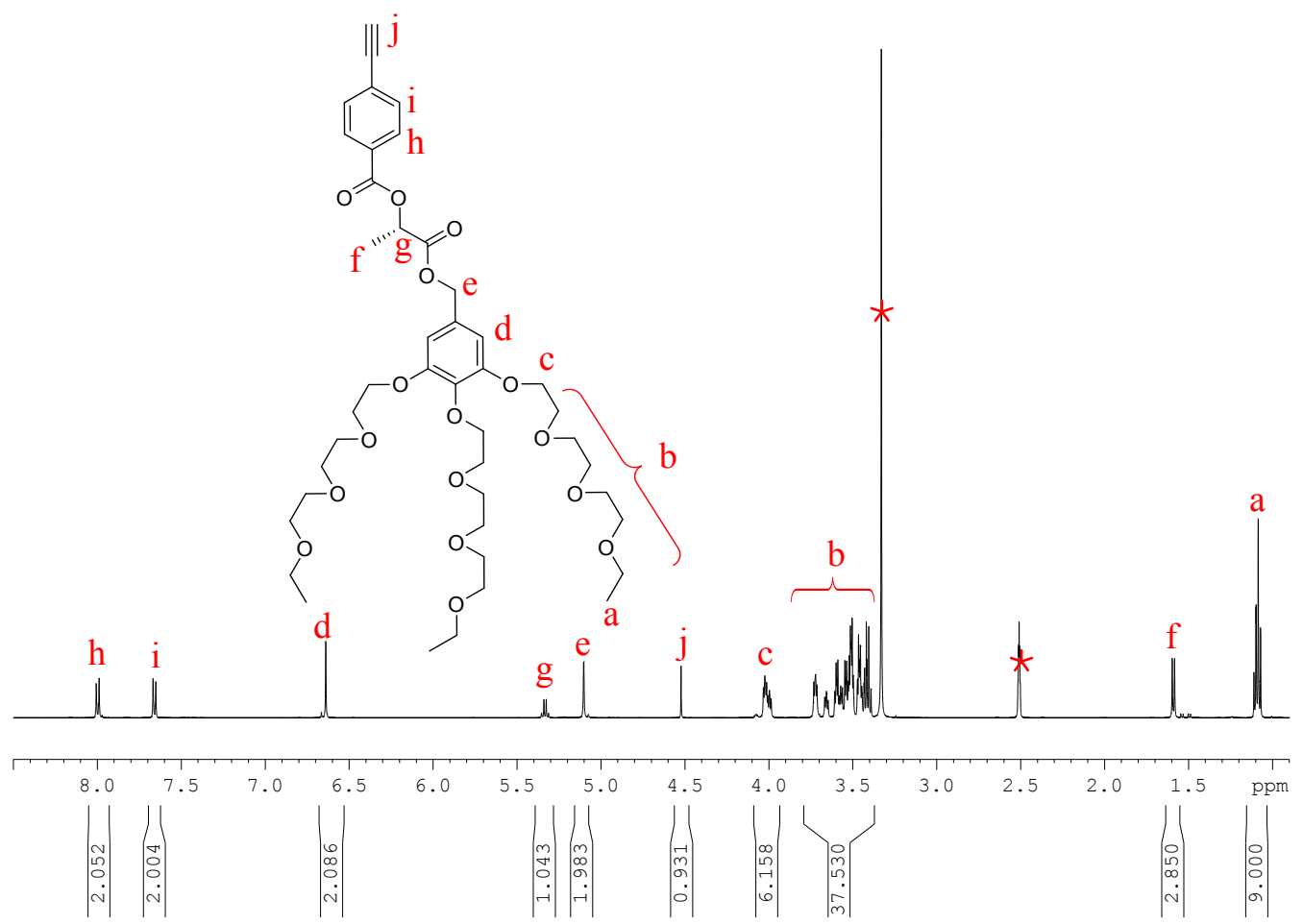

Figure S3. ${ }^{1} \mathrm{H}$ NMR spectrum of monomer PA-ES in $\mathrm{d}_{6}$-DMSO. The solvent peak is marked with asterisk $(*)$.

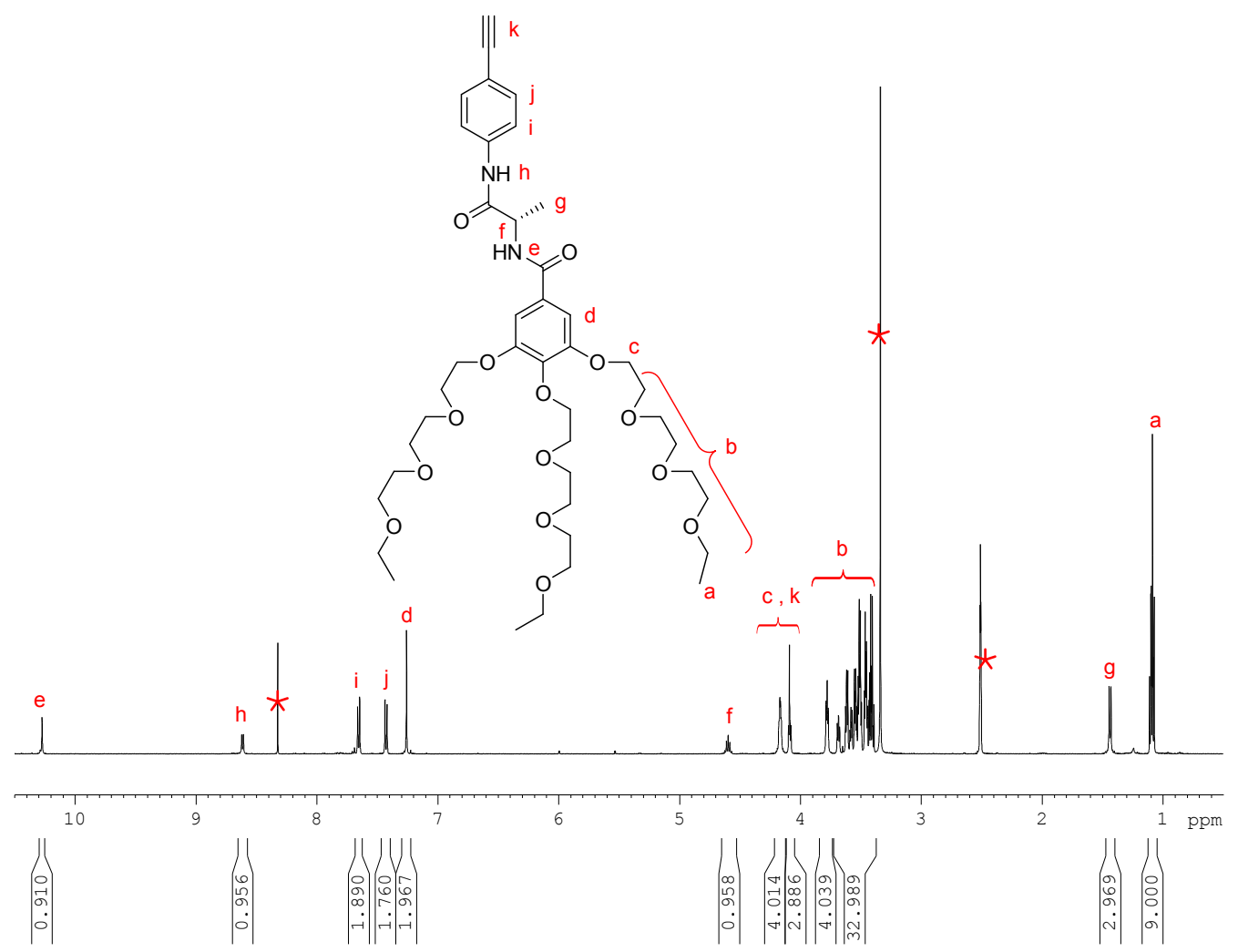

Figure S4. ${ }^{1} \mathrm{H}$ NMR spectrum of monomer PA-dAM in $\mathrm{d}_{6}$-DMSO. The solvent peak is marked with asterisk $(*)$. 


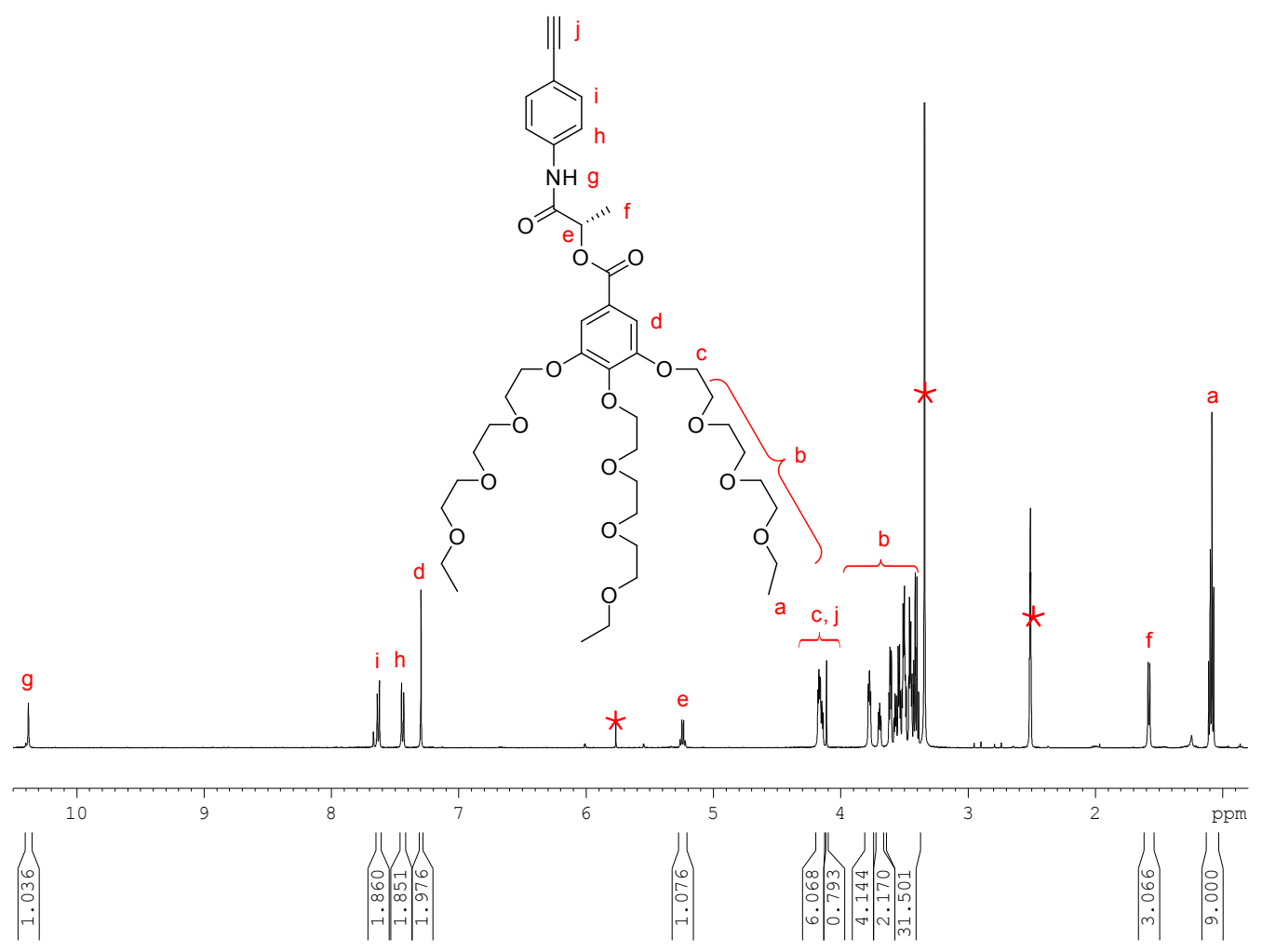

Figure S5. ${ }^{1} \mathrm{H}$ NMR spectrum of monomer PA-AM in $\mathrm{d}_{6}$-DMSO. The solvent peak is marked with asterisk $(*)$.

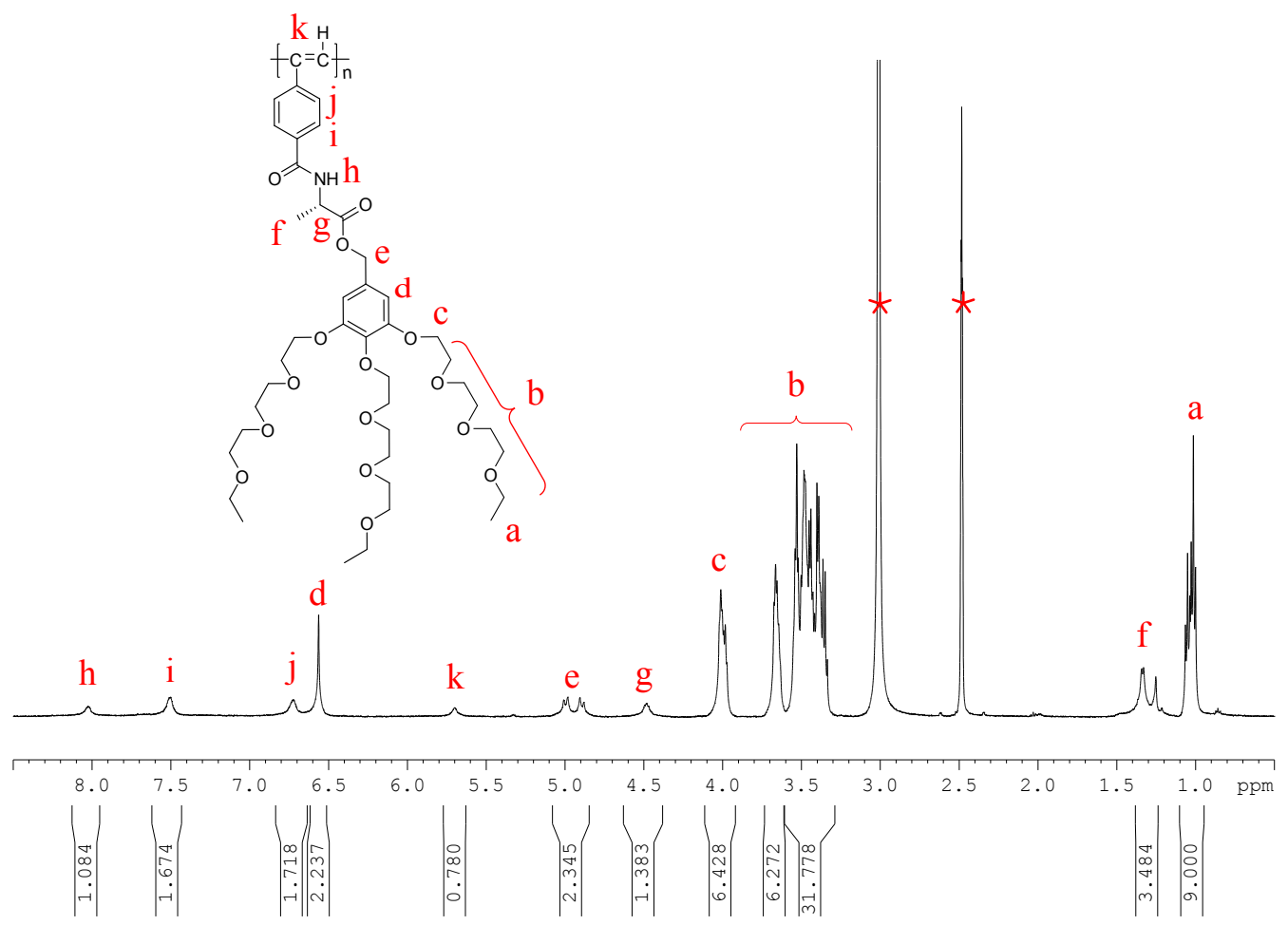

Figure S6. ${ }^{1} \mathrm{H}$ NMR spectrum of compound PPA-ACe in $\mathrm{d}_{6}$-DMSO. The solvent peak is marked with asterisk $(*)$. 


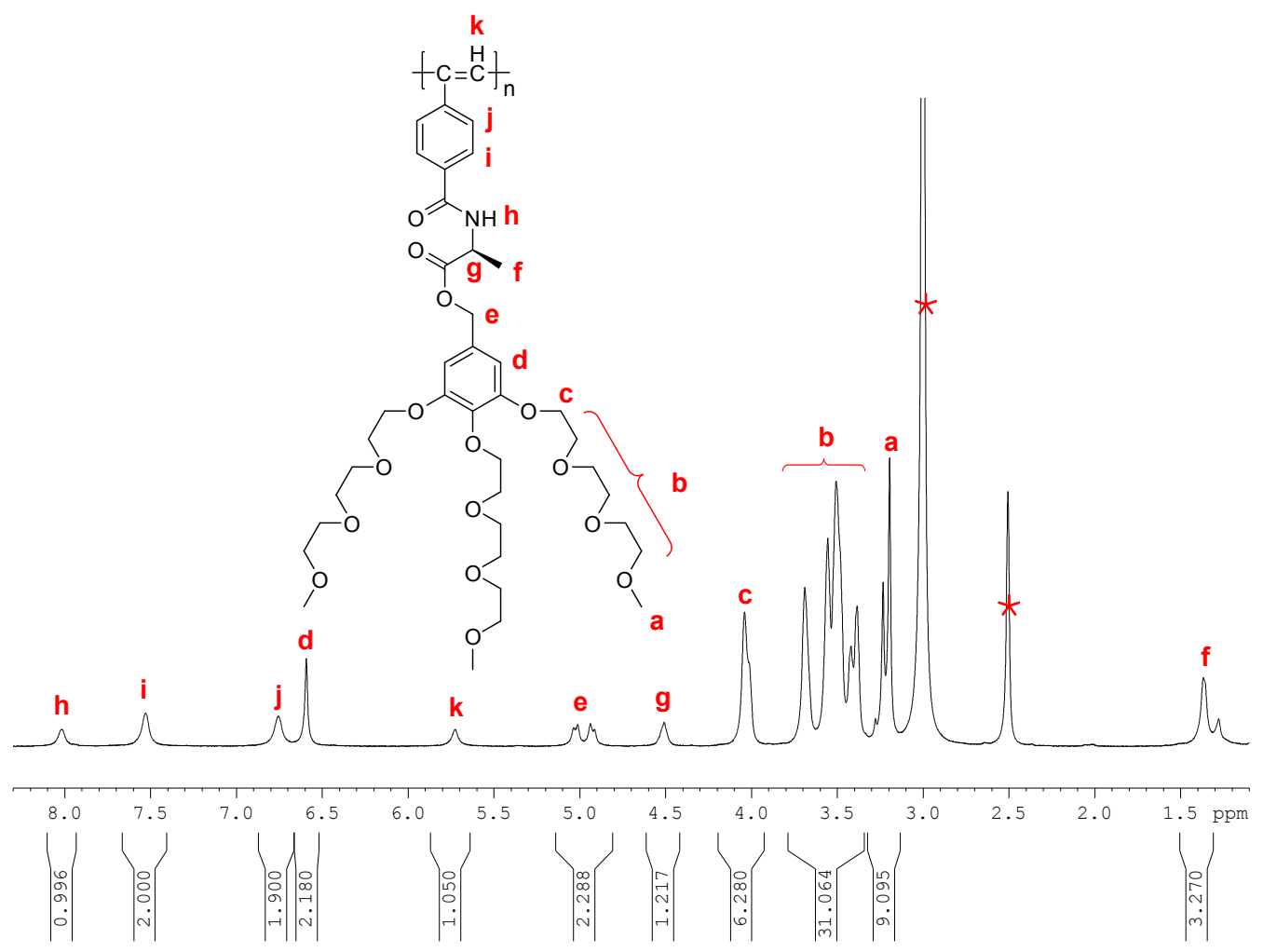

Figure S7. ${ }^{1} \mathrm{H}$ NMR spectrum of compound PPA-ACm in $\mathrm{d}_{6}$-DMSO. The solvent peak is marked with asterisk $(*)$.

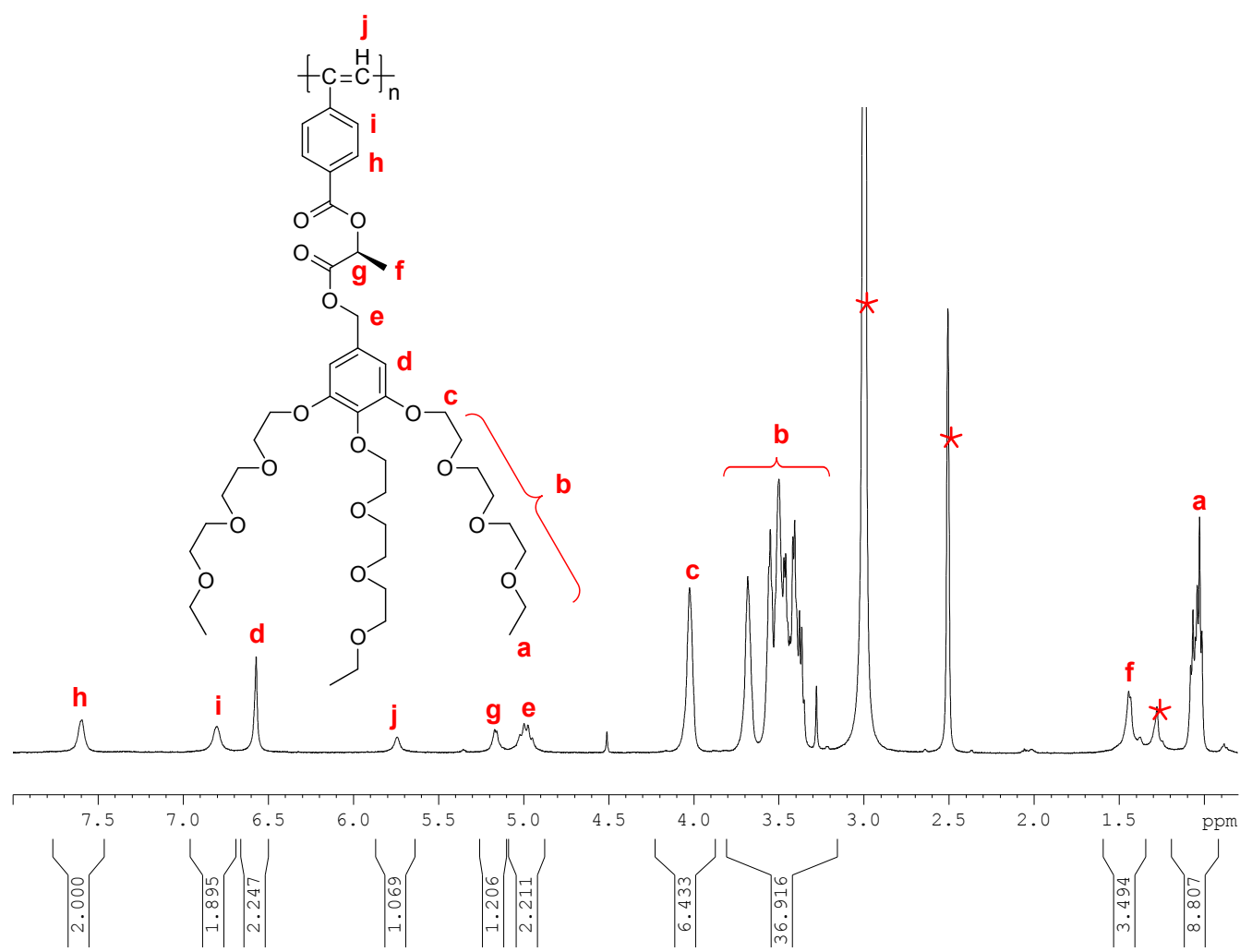

Figure S8. ${ }^{1} \mathrm{H}$ NMR spectrum of compound PPA-ES in $\mathrm{d}_{6}$-DMSO. The solvent peak is marked with asterisk $(*)$. 


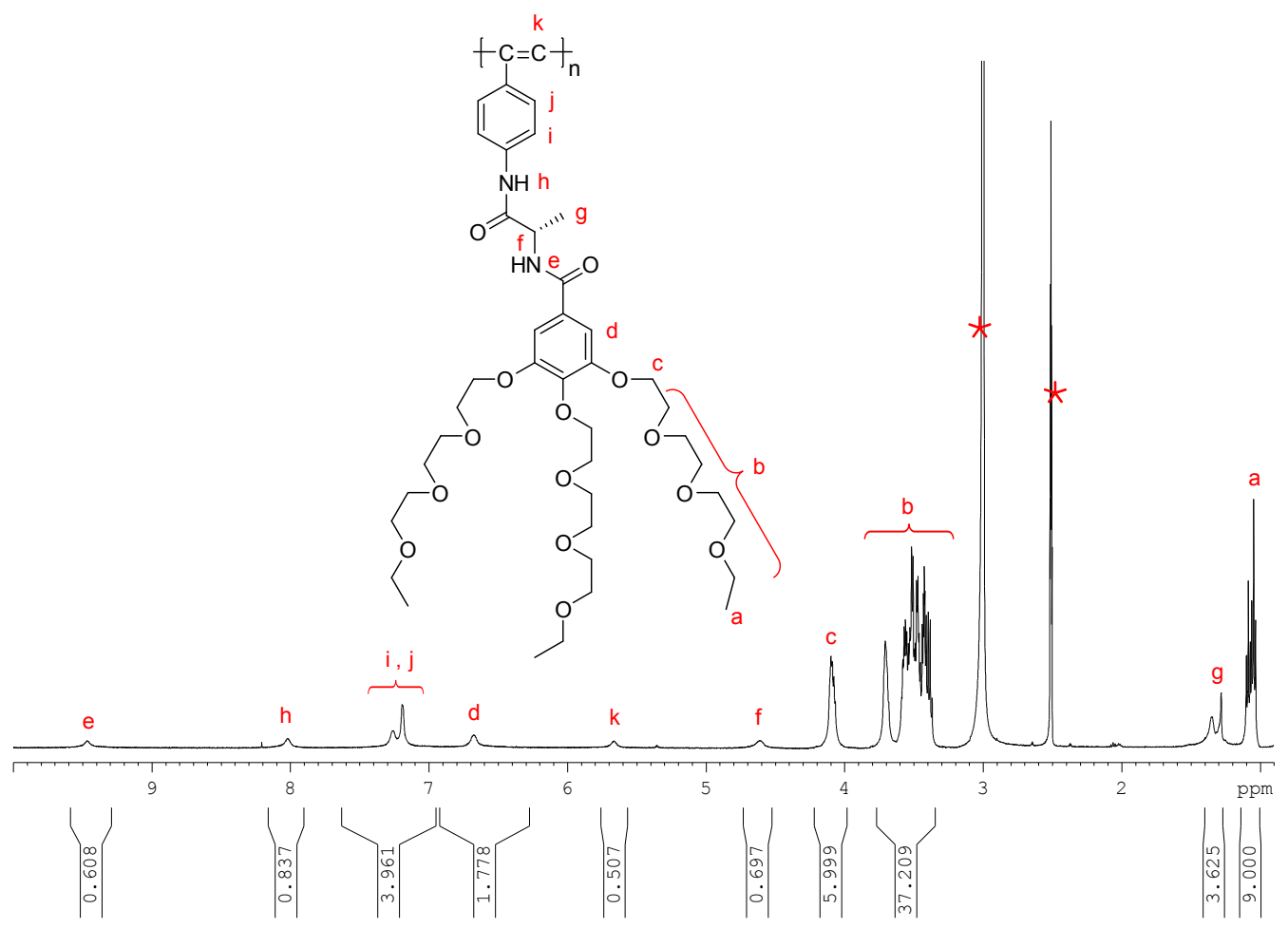

Figure S9. ${ }^{1} \mathrm{H}$ NMR spectrum of compound PPA-dAM in $\mathrm{d}_{6}$-DMSO. The solvent peak is marked with asterisk $(*)$.

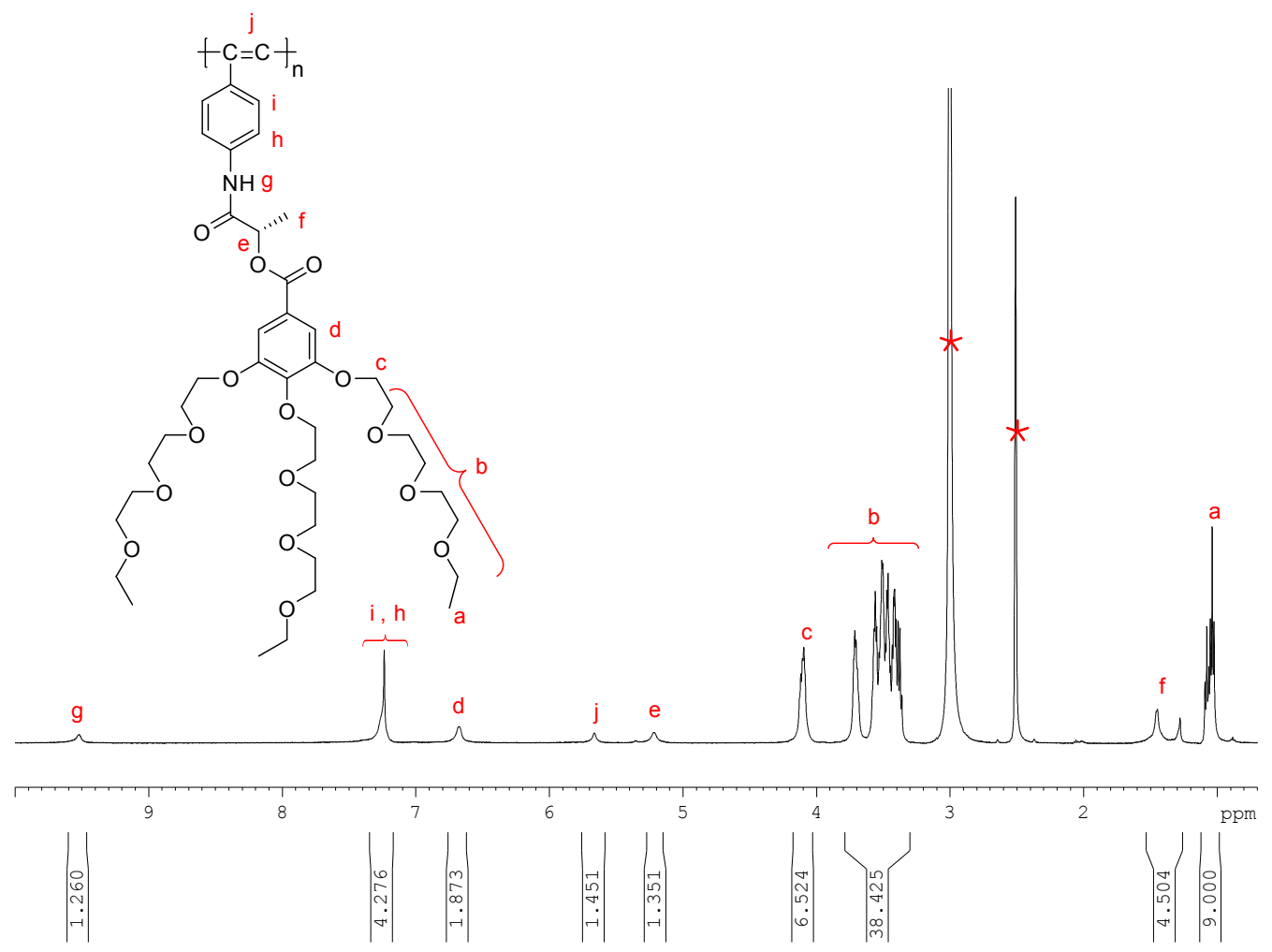

Figure S10. ${ }^{1} \mathrm{H}$ NMR spectrum of compound PPA-AM in $\mathrm{d}_{6}$-DMSO. The solvent peak is marked with asterisk $(*)$. 


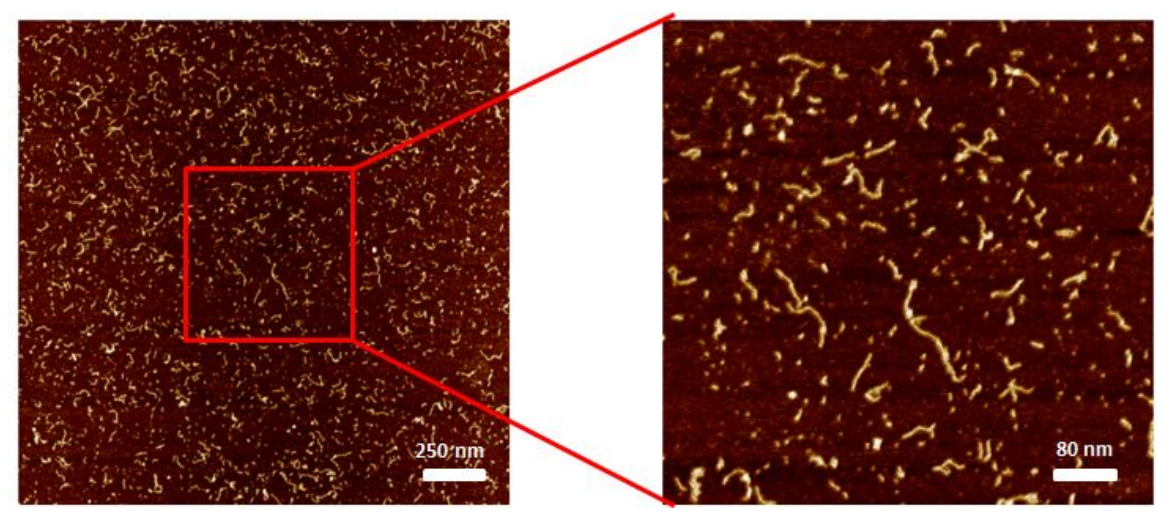

Figure S11. Atomic force microscopy (AFM) image of PPA-ACm from THF solution $(0.002 \mathrm{mg} / \mathrm{mL})$.

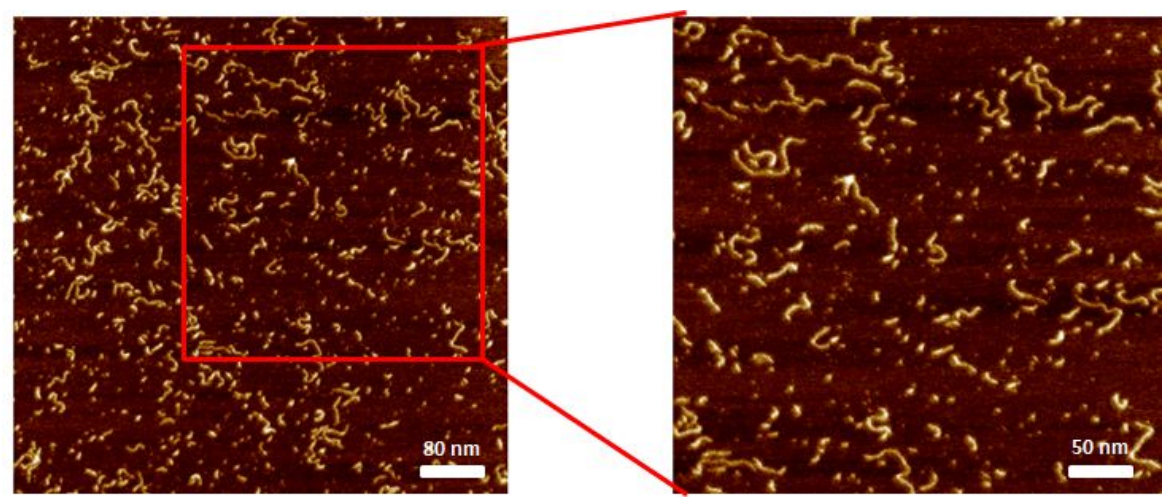

Figure S12. Atomic force microscopy (AFM) image of PPA-ACe from THF solution $(0.002 \mathrm{mg} / \mathrm{mL})$.

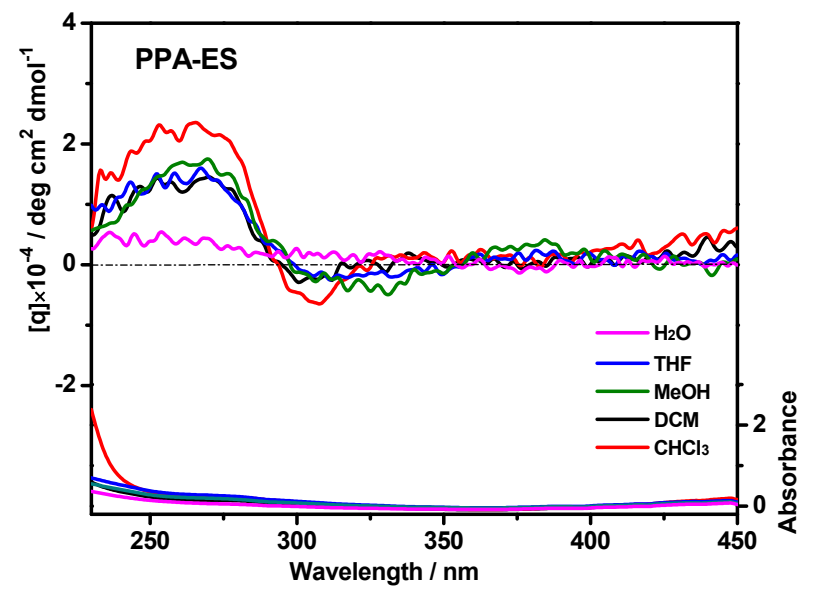

Figure S13. CD and UV-vis spectra of PPA-ES $(0.25 \mathrm{mg} / \mathrm{mL})$ measured in $\mathrm{H}_{2} \mathrm{O}$, THF, $\mathrm{MeOH}, \mathrm{DCM}$ and $\mathrm{CHCl}_{3}$ at $25{ }^{\circ} \mathrm{C}$. 


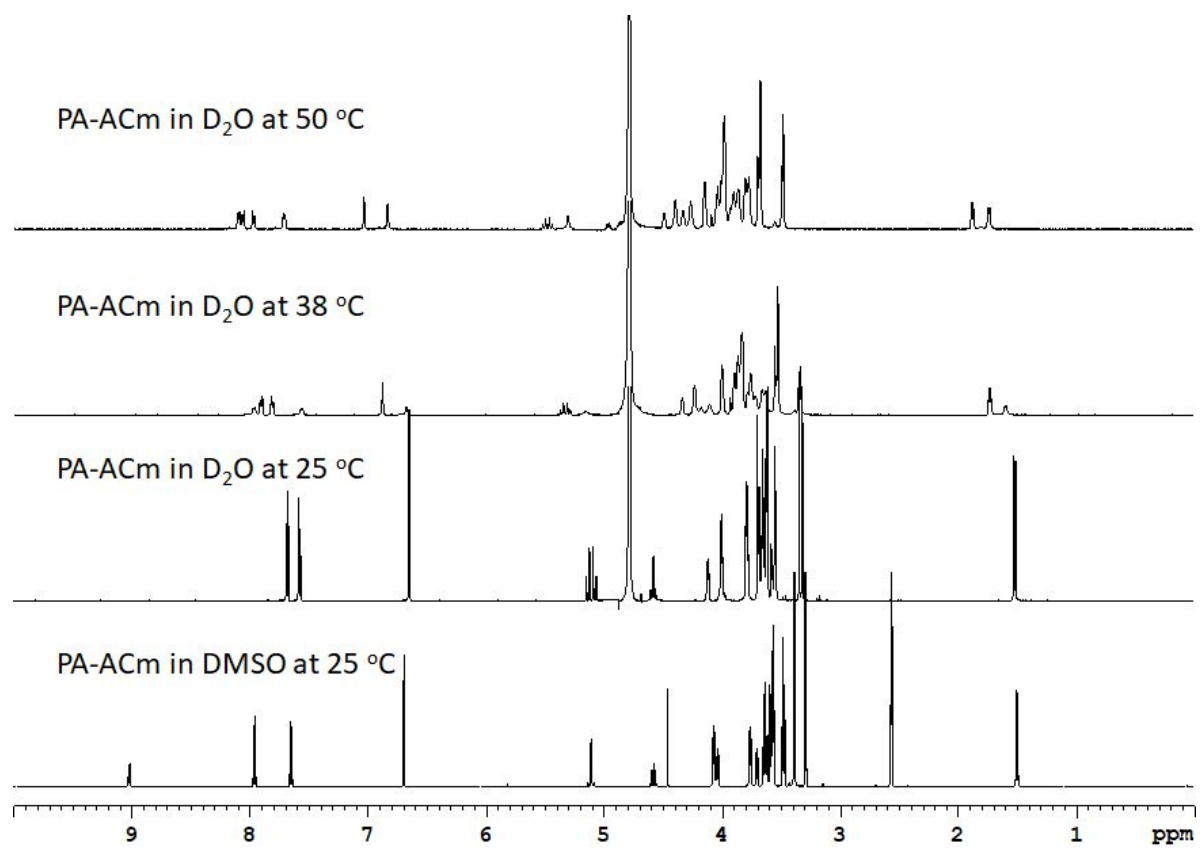

Figure S14. ${ }^{1} \mathrm{H}$ NMR spectra of monomer PA-ACm at various temperatures in $\mathrm{D}_{2} \mathrm{O}$, as well as in $\mathrm{d}_{6}$-DMSO at $25^{\circ} \mathrm{C}$.

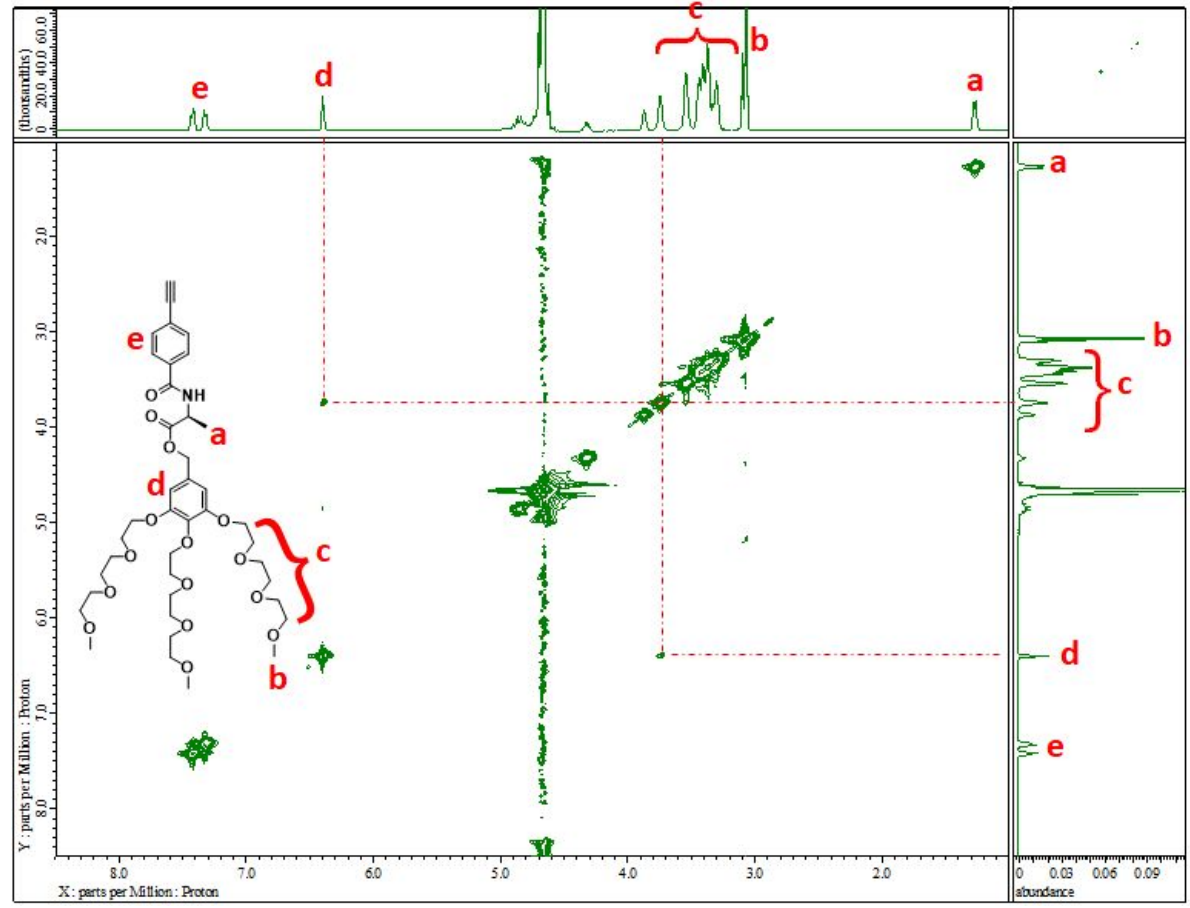

Figure S15. ${ }^{1} \mathrm{H}-{ }^{1} \mathrm{H}$ NOESY spectrum of monomer PA-ACm in $\mathrm{D}_{2} \mathrm{O}$ at $10{ }^{\circ} \mathrm{C}$. Mixing time $1000 \mathrm{~ms}$. 


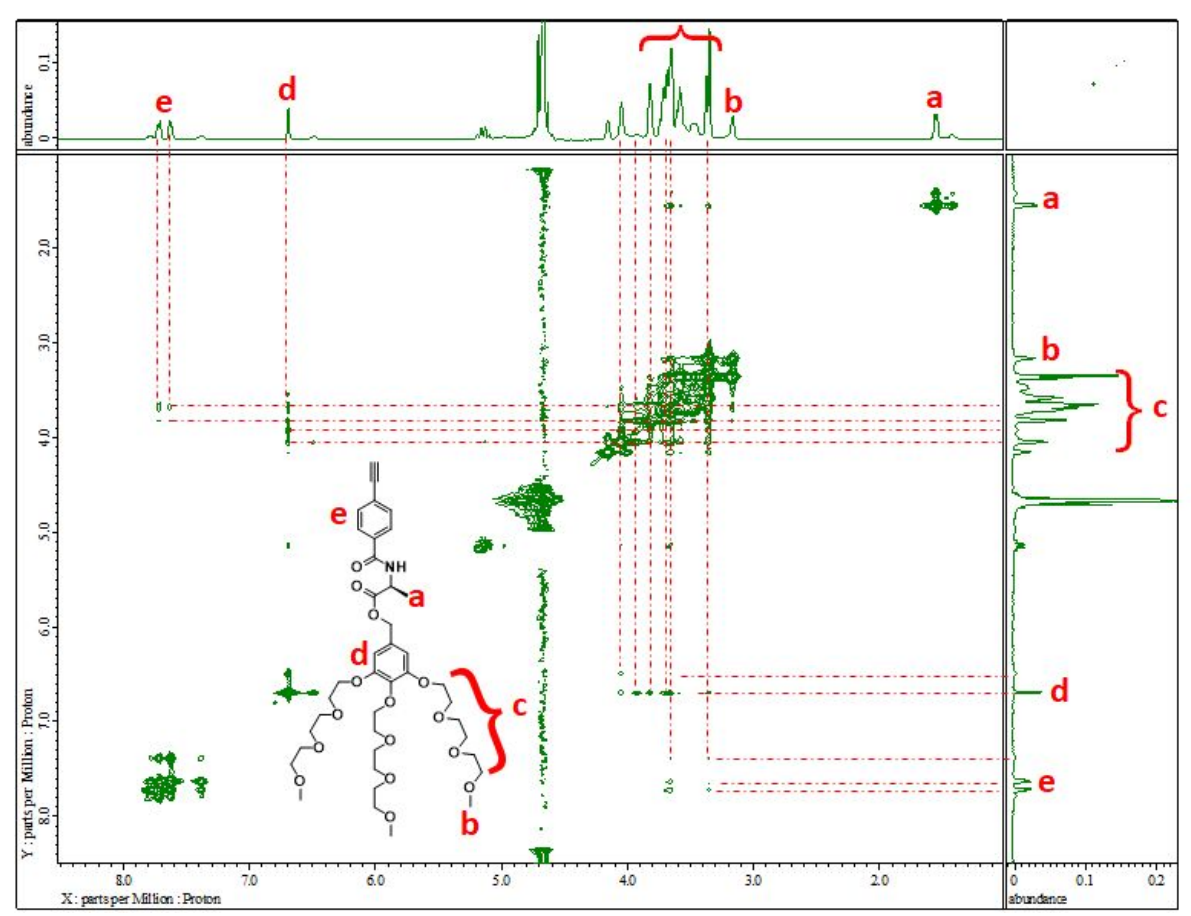

Figure S16. ${ }^{1} \mathrm{H}-{ }^{1} \mathrm{H}$ NOESY spectrum of monomer PA-ACm in $\mathrm{D}_{2} \mathrm{O}$ at $38{ }^{\circ} \mathrm{C}$. Mixing time $1000 \mathrm{~ms}$.

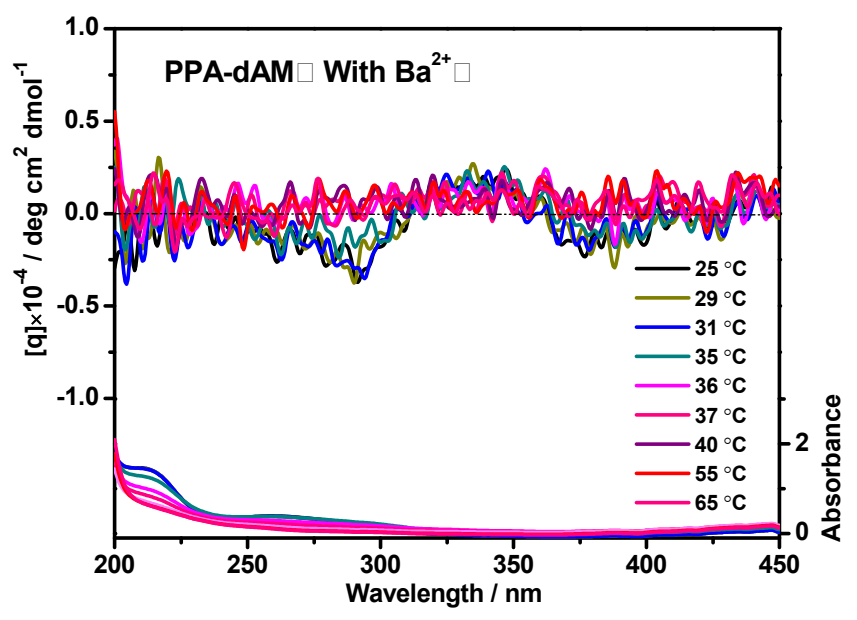

Figure S17. Temperature variable CD spectra of PPA-dAM $(0.025 \mathrm{mg} / \mathrm{mL})$ taken after the addition of $\mathrm{BaCl}_{2} \cdot \mathrm{H}_{2} \mathrm{O}(0.25 \mathrm{mg} / \mathrm{mL})$. 